DOI 10.37882/2223-2982.2021.09-2.07

\title{
КОНЦЕПТ «ВЕЖЛИВОСТЬ» В ДЕЛОВОЙ ПЕРЕПИСКЕ И СРЕДСТВА ЕЕ ВЫРАЖЕНИЯ
}

\section{THE CONCEPT OF "POLITENESS" IN BUSINESS CORRESPONDENCE AND THE MEANS OF ITS EXPRESSION}

\section{S. Gurbanova}

Summary: The article analyzes the concept of "politeness" in business correspondence. It should be noted that today the vast majority of companies and enterprises with international relations are in urgent need of employees who already have written and oral speech skills, as well as some knowledge of clerical issues. Thus, they should achieve the development of business correspondence in English. In addition, in the era of widespread use of information and communication technologies, one of the important issues is the development of specialists working in various fields, the ability to achieve their goals using electronic means in accordance with the requirements of the day. At the same time, special courses should be organized for specialists working in companies and at the international level. During these courses, the attention of participants should be focused on the linguistic and cultural aspects of communication, instilling the skills and abilities necessary for the successful implementation of business activities in various countries of the world. One of the main goals of such courses is to instill the norms of intercultural communication in English to specialists working in various fields, to prevent difficulties and problems that may arise in the process of communication and documentation, to eliminate factors that may hinder this process.

Keywords:strategy, politeness, speech, language, maxim, correspondence, concept.

\author{
Гурбанова Саида Сади гызы \\ Азербайджанский университет языков \\ saidag8@rambler.ru
}

Аннотация: (татья посвящена концепту «вежливость» в деловой переписке. Следует отметить, что сегодня подавляющее большинство компаний и предприятий, имеющих международные связи, остро нуждаются в сотрудниках, которые уже обладают навыками письменной и устной речи, а также в некоторой степени владеют канцелярскими вопросами. Таким образом, они должны достичь развития деловой переписки на английском языке. Кроме того, в эпоху широкого использования информационно-коммуникационных технологий одним из важных вопросов является развитие у специалистов, работающих в различных областях, способности достигать своих целей, используя электронные средства в соответствии с требованиями дня. В то же время должны быть организованы специальные курсы для специалистов, работающих в компаниях и на международном уровне. Во время проведения этих курсов внимание участников должно быть сосредоточено на лингвистических и культурных аспектах общения, привитии умений и навыков, необходимых для успешного осуществления деловой активности в различных странах мира. Одной из основных целей проведения таких курсов является привитие норм межкультурной коммуникации на английском языке специалистам, работающим в различных областях, предотвращение трудностей и проблем, которые могут возникнуть в процессе общения и документирования, устранение факторов, которые могут препятствовать этому процессу.

Ключевые слова: стратегия, вежливость, речь, язык, максима, переписка, концепт.

устной форме, «говорим» языком документов, написанных слов и фраз. Это способствует тому, что развитие различных сфер, в том числе деловой переписки, становится требованием дня. В глобализирующемся мире в период развития многоплановых связей между различными странами наблюдается их расширение. Учитывая растущую потребность и спрос на этот механизм передачи информации, встает вопрос о построении деловой переписки на более серьезных научных основаниях. Это также требует, чтобы анализ различных аспектов рассматриваемой области был более адаптирован к потребностям сотрудников. Основной целью здесь является обучение персонала навыкам и способностям, используемым в академических и неакадемических ситуациях, которые напрямую связаны с их квалификацией. В связи с этим необходимо выделить как академические, так и обычные, универсальные ситуации, актуальные для данной области, то есть с которыми могут столкнуть-

Иногда, когда мы не можем передать информацию в

1. целостностью

2. трансформацией

3. самоуправлением 
ся специалисты, работающие в этой области. Язык этих ситуаций и соответствующие документы должны быть лингвистически проанализированы.

Выявление языковых особенностей, присущих отдельным ситуациям, определенных в результате проведенного лингвистического анализа, должно стать основой деловой переписки. Текст является носителем и передатчиком информации. В тексте информация последовательно меняется, языковые элементы формируют общее содержание. При этом адресату предоставляется различная информация. Но процесс отправки текста продолжается до тех пор, пока конечная цель не будет сформулирована и передана адресату основная информация - весь текст. Пока текст не закончен, в нем можно найти различные цепные и параллельные связи. Структурирование информации при международной переписке предполагает определенную последовательность процедурных правил. Таким образом, отправитель текста должен, во-первых, выбрать необходимые слова из словарного состава, затем на синтаксическом уровне заняться словосочетаниями и построением предложений и, наконец, определить, как оба уровня могут быть использованы в тексте. При этом многие языковые, психологические, социальные, культурные, и другие факторы влияют на этот выбор. Исследования показывают, что структурирование информации определяет успех понимания в процессе переписки. Хорошо сформированная мысль, идея, которая имеет логическую структуру, лучше понимается, воспринимается. Поэтому при передаче той или иной информации важное значение имеет правильный порядок последовательности предложений. Исследователь Э. Мусаев пишет, что документ - это не фиксация информации, событий, фактов, каких-либо конкретных материалов, которые возникли из человеческой мысли. Документ - средство закрепления и переноса различными способами информации о фактах, явлениях, обстоятельствах объективной и мыслительной деятельности человека на специальном материале [2, с.18]. Следует также подчеркнуть, что важно овладение аспектами иностранного языка, лексическими единицами и грамматическими структурами, существующими в языке, и развитие способности адекватно использовать язык в коммуникативных целях. При написании любого текста, особенно деловой переписки, стратегии вежливости обязательно должны быть подобраны и учтены соответствующим образом.

Слово вежливость происходит от латинского слова "politus". Если рассмотреть суть этих слов, то это проявляется в определенных отношениях как позитивная социальная оценка. В ходе любой беседы и общения слушатель или говорящий выбирает позицию самозащиты: человек А использует определенные просодические элементы, чтобы привлечь внимание человека В. Кроме того, выделяются три разновидности:

1. Distance (D) - это социальное измерение сходства и различия. Определяется частотой интеракции между говорящим и слушающим. Отправка положительной взаимной оценки в это время является признаком социальной близости.

2. Relative Power (P) - это асимметричное социальное измерение. Это планы участника и степень его самооценки.

3. Absolute Ranking (R) - это отношение интеракционистов к ситуациям и культурам, к которым они принадлежат. Предположим, кто-то хочет одну чашку чая от своего коллеги. Естественно, это варьируется в зависимости от ситуации и личности. Так, кто-то воспримет это как команду, а другой как давнее знакомство.

В исследованиях отмечается 2 вида вежливости: позитивная и негативная. Позитивная вежливость предназначена для того, чтобы все было так, как человек хочет. В это время отождествляются интересы говорящего и слушающего. В негативной вежливости, как будто у человека возникает ощущение отсутствия мыслей. В это время на ум приходит понятие расстояния. И это происходит тогда, когда негативная вежливость уже существует. В литературе оценивают невежливость следующим образом:

а) говорящий целенаправленно подключается к"faceattack".

б) слушатель целенаправленно делает "face-attacking".

Эту разработку следует понимать как основную суть термина невежливости. Были попытки найти новые ракурсы в исследованиях и определить влияние этого на общение. Это также называется «broad opposite of politeness». Например, фраза have a good day может использоваться в различных ситуациях и контекстах. Таким образом, может случиться так, что это выражение имело положительное значение в одном контексте и отрицательное - в другом.

Одна из теорий Дж.Лича заключается в изучении различий между абсолютной и относительной вежливостью. Абсолютная вежливость заключается в минимизации невежливости и максимизации вежливости.

Абсолютная вежливость - это ассоциация вежливости с типами речевых актов. Она охватывает позитивную и негативную сферы одновременно. Речевые акты, такие как предложения, являются интринсивными, то есть внутренней вежливостью, но команды - интринсивной невежливостью. Относительная вежливость - это соотношение норм как неприятного аспекта критики. "Modesty Maxim" и "Approbation Maxim" ориентированы на самокритику и самооценку, а также на критику окружающих. 
Эта относительность является основной проблемой носителей языка в принципе вежливости (РP). Это также серия «maxim» для РP, которые включают в себя:

\section{Tact Maxim}

а. минимизирует оценку, данную другим

б. максимизирует выгоду для других

II. Generosity Maxim

а. уменьшает пользу для себя

б. повышает самооценку

III. Approbation Maxim
а. сводит к минимуму хвалу других
б. сводит к максимуму хвалу других

VI. Modesty Maxim

а. минимизирует самохваление

б. максимизирует самокритику

V. Agreement Maxim

а. сводит к минимуму недопонимание между собой

и другими

б. максимизирует согласие между собой и другими

IV. Sympathy Maxim

а. сводит к минимуму антипатию между собой и другими

б. максимизирует симпатию между собой и другими

«Tact Maxim» в основном используется в негативной вежливости (веление, уважение, давать команду, совет, рекомендация, приглашение, обещание, предложение и т.д.). Эти иллокутивные действия относятся к действиям, выполняемым слушателями и говорящими. Деятельность, выполняемая в рамках этого "maxim", оценивается по оценке и выгоде для S и Н. Это может быть достигнуто с помощью шкалы «cost-benefit» [4, с. 45]. «Generosity Maxim» часто функционирует вместе с «Tact Maxim». Это относится к тем, кто невежлив. Существует предположение, что "Tact Maxim" и "Generosity Maxim" демонстрируют больше эмфатичности и приводят к невежливости. Так, в процессе оценки "Н" главный ориентир забывается и выбирается целенаправленная деятельность и цели в пользу "S".

"Approbation Maxim" предпочитает говорить о неприятных вещах. Особенно это происходит, когда упомянутые вопросы касаются слушателя. Стратегии непосредственности, основанные на принципе вежливости (РP), позволяют говорящему сбалансировать неприятные аспекты критики. "Modesty Maxim" в сочетании с "Approbation Maxim" воспринимает критику окружающих как их невежливость. Наблюдение "Modesty Maxim" основано на относительности. Следующими по вежливости считаются "Agreement Maxim" и "Sympathy Maxim". "Agreement Maxim" ищет возможности для того, чтобы говорящий, с одной стороны, достиг согласия в максимальных пределах, а с другой стороны, выражая сожаление, ищет возможности выразить половинчатое недовольство. Говорящие во время "Sympathy Maxim" минимизируют антипатию к окружающим, максимизируют симпатию. Дж. Лич считает, что не все "Maxim" имеют одинаковое значение. Он отмечает, что "Tact Maxim" и "Approbation Maxim" более важны, чем "Generosity Maxim". Согласно его идее, концепт вежливости требует большей ориентации на другого человека (адресата), чем на него самого. Он отмечает, что внутри каждого "maxim" есть 2 "submaxim". Каждый "maxim" гораздо важнее, чем 2 "maxim" внутри. Автор отмечает, что негативная вежливость требует больше исследований (поиск понимания), чем позитивная вежливость, за исключением разногласий [4, c. 64].

Отметим, что принцип вежливости Дж.Лича был нормально встречен критиками. Некоторые, однако, начали думать, что это несколько проблематично. Тем не менее, новое "maxim" может быть выдвинут за регулярность использования любого языка. Это было показано во многих исследованиях. Вторая цель критики РР была связана с тем, что Дж.Лич приравнивал вежливость к посредничеству. Эта идея вызвала немало дискуссий. Они считали, что прямое звучание может быть подходящей формой невежливости в речевой ситуации. Кстати, нужно обратить внимание, что "Face System" состоит из трех компонентов, которые включают в себя:

1. Deference Face

2. Solidarity Face

3. Hierarchy Face [6, c. 33-49].

Они основаны на разнице и расстоянии между участниками. "Deference Face System" - это система, в которой участники поддерживают дистанцию друг от друга. Здесь противоположные стороны используют стратегии раскрепощения, отворачиваются друг от друга и тем самым возбуждают друг друга. Во время "Solidarity Face" участники считают друг друга близкими в социальных ситуациях, проявляют чувства дружбы и близости. Во время "Hierarchy Face", которое является последним компонентом, асимметричные отношения составляют доминирование, люди признают и уважают социальные различия. Здесь одни из них находятся в главном положении "superordinate", а другие - в зависимом "subordinate". В это время тот, кто занимает доминирующее положение, может использовать любые стратегии иерархической системы, чтобы не отворачиваться от другого человека, занимающего высокое положение. Таким образом, вежливость - это явление общечеловеческое, над которым работали многие исследователи. Р. Лакоф отмечает, что вежливость предназначена для уменьшения противоречий со стороны общества во время личного взаимодействия [5, с.64]. Р. Лакоф с уверенностью отмечает, что для того, чтобы знать, является ли языковой акт вежливым или грубым, должен быть набор правил и принципов. Он должен быть изучен в разных культурах и языках, чтобы сформировать правила [5, с.87]. Таким образом, вы- 
сокий уровень овладения английским языком, который имеет особое значение в современном мире и является основным средством коммуникации в эпоху глобализации, является одним из основных требований, стоящих перед учебными заведениями. Необходимость изучения английского языка как средства общения сегодня неоспорима. В то же время следует отметить, что те, кто изучает английский язык, склонны использовать этот язык как средство общения. Используя передовые технологии через английский язык, люди приобретают способность извлекать выгоду из мирового опыта, связанного с их профессиональной сферой, и эффективно использовать его, усваивая необходимые знания. И здесь мотивационный фактор обусловливает шаг к успеху, являясь самым передовым процессом. Правильное использование стратегий вежливости в процессе формирования межкультурной компетентности также свидетельствует о достижении успешных результатов. В это время особенно важным считается мотивирующее общение. Так, в литературе в связи с этим отмечается шесть формульных типов мотивации “Cs". Они состоят из:

1. Возможность выбора (choice)

2. Мотивация (challenge)

3. Контролировать (control)

4. Сотрудничать (collaboration)

5. Смысловой синтез (Constructing meaning)

6. Заключение (consequences).

Вопросы мотивации формирования межкультурной компетентности в иностранном языке всегда были одной из важнейших проблем, стоящих в центре внимания исследователей, которые не теряют свою актуальность и сегодня. Существует также девять когнитивных компонентов, которые занимают особое место в формировании межкультурной компетентности:

1. Ловкость (fluency);

2. Словарь (vocabulary);

3. Научное мировоззрение (world knowledge);

4. Мотивация (motivation);

5. Определение целей и задач (purposes, goals);

6. Когнитивные и мета-когнитивные стратегии (cognitive and meta-cognitive strategies);

7. Знание языка (linguistic knowledge);

8. Формирование знаний о дискурсе (discourse knowledge);

9. Интеграция с информацией, содержащей текст (integrating non-print information with text).

Следует отметить, что правильный выбор стратегий вежливости играет важную роль в развитии межкультурной компетентности. Конечно, здесь работа напрямую зависит от емкости общения и мотивации. При этом стороны также могут использовать свой опыт. В этом отношении А. Мамедов, М. Мамедов пишут: «Дискурс, объясняя общие стороны познавательного механизма человека, устанавливает связь между универсальным и культурным концептами. Инференция, понимание и интерпретация одного и того же универсального концепта и его лингвистических и риторических репрезентаций могут быть разными как в дискурсе, принадлежащем к одной культуре, так и в поликультурном дискурсе. Поэтому оба типа концепта являются основными источниками коммуникативного динамизма в дискурсе. Причина этих различий заключается в том, что отношения между языком и культурой очень специфичны в каждом языковом факте» [1, с.99]. Дело в том, что эти ассоциации, о которых мы говорим как о культурном понятии в художественном дискурсе, иногда выходят за пределы одного народа и проникают в сферу другой культуры. Одна из важных проблем для этого фактора заключается в том, что эти метафоры занимают центральное положение, а не периферийное поле когнитивной модели.

Таким образом, отправитель текста использует лингвистические (существительные, временные формы глагола, пространственно-временные наречия, указательные, личные и притяжательные местоимения, артикли, суффиксы и др.) и риторические (метафора, метонимия и т.д.) средства для репрезентации в дискурсе универсальных понятий и их определяющих параметров. Эти лингвистические и риторические средства на самом деле можно рассматривать как инструменты концептуализации. Интересен тот факт, что процесс концептуализации реализуется, прежде всего, в дискурсах, принадлежащих разным языкам и культурам [1, с.72]. Несмотря на общий для носителей языка характер фонетического состава языка, чередования звуков, видоизменения фонем в речевом потоке, акцентуации и интонации, звуковые законы воспринимаются не всеми одинаково. В зависимости от индивидуальных особенностей говорящего, местных условий и других причин произносительные нормы нарушаются, искажаются. С коммуникативной точки зрения следует рекомендовать сравнительный анализ и сравнение речевых и структурных моделей, соответствующих конкретным коммуникативным ситуациям. Проведение сравнительного исследования в этом направлении помогает выявить наличие аналогичных коммуникативных ситуаций, существующих в языке, а также ситуаций, свойственных только одному из сравниваемых языков. Выше мы отметили, что одной из главных целей сегодня является формирование межкультурной компетентности между народами. Это также предполагает развитие вербальных и невербальных навыков общения людей в ситуации, когда иностранный язык является естественным средством общения. Здесь крайне важно усвоение людьми, как языковой системы, так и норм ее применения в различных коммуникативных ситуациях. Еще одна цель - развивать мышление. Одной из целей его изучения является вопрос развития логического мышления. Вступая в общение, стороны стараются все сравнить, 
сделать выводы. Они уже умеют классифицировать, высказывать мнение, сравнивая их, выделять слова в предложении, звуки в словах, подсказывать правило, касающееся каждого из них. А это положительно сказывается на мотивационном фоне. Они не могут овладеть мышлением через какие-либо слова или выражения, даже при изучении иностранного языка. Стороны должны помнить, что при общении они воспринимают много информации, и такая информация положительно влияет на развитие их логического мышления. Обратим внимание, что если кто-то хочет быть способным коммуникатором, он должен знать каждый из четырех навыков. Этими навыками считаются говорение, чтение, письмо, аудирование. Они также кратко называют их «LSRW». Использование этих четырех навыков делает коммуникаторов более мотивированными в важных вопросах, таких как передача идей о реальных событиях, использование соответствующих стратегий, обмен своими чувствами и волнением. Отметим, что подход "from one to form four" является обязательным условием в овладении рассматриваемыми навыками. При общении следует учитывать включение в содержание интересов сторон, уровень чувства юмора и т.д. Их слабые и сильные стороны должны быть раскрыты. Кроме того, стороны должны работать и быть уверены, что:

- нормальные условия полностью обеспечены;

- звук и дополнительные движения удалены;

- следует искать, учитывать фонологические особенности (ассимиляция, многоточие и др.)

- скорость речи не быстрее, чем скорость прослушивания.

Во время общения считается целесообразным использование стратегий вежливости. Нужно постараться, чтобы темы, предназначенные для успешного общения, строились вокруг актуальных вопросов. Кроме того, следующие стратегии также важны:

1. Defining terms (определить термины). Это важно, хотя это кажется простым.

2. Summarizing positions (провести суммирование). В большинстве случаев возникает необходимость дать краткое толкование. В это время нужно уметь делать обобщения.

3. Metaphor (Метафора). Использование метафор это формирование дополнительного взгляда на нашу речь, добавление оттенков. Когда метафора используется, оттенок добавляется к исходной идее.

Рассматривая коммуникативно-ориентированность в реализуемых стратегиях, целесообразно выделить следующие:

- Интенсивный разговор. Они поддерживают быструю речь.

- Беседа. Под этим подразумевается диалогическая речь, основанная на совместном общении. Здесь реплика сторон направляет их и помогает структурировать свою речь с структурно-синтаксической точки зрения.

Кроме того, мотивирующие реплики создают условия для отражения информации личностного характера. Это также вопрос, который напрямую связан с коммуникативными ситуациями и социальными ролями участников мероприятия.

Наконец, когда стороны достигают достаточного уровня, они активно участвуют в устном речевом общении, выражаясь обширными рапортами, монологическими комментариями и т.д.

Люди предпочитают быть более креативными. Это обеспечивает развитие критического мышления и позволяет эффективно организовать процесс общения в целом и добиться успешных результатов. Они, в свою очередь, должны подходить к ним как к разным индивидуумам с разными интересами, направляя их на закрепление различных позиций и развитие в процессе общения способности к достижению консенсуса. При этом обязательно должно учитываться и количество сторон. Так, обсуждения, беседы должны быть организованы таким образом, чтобы все участвующие стороны могли извлечь максимальную пользу. Таким образом, стратегии, используемые в формировании межкультурной компетентности, должны строиться в соответствии с возрастом, интересами и потребностями сторон. В этом отношении Грайс Пол говорит о четырех кооперативных принципах, которые предназначены для обеспечения максимального общения.

\section{Maxim of Quantity}

а) делай свою помощь информативной, как требуется (с целью постоянных изменений)

б) не делай свою помощь более информативной чем это требуется

\section{Maxim of Quality}

а) реализуй собственную помощь

б) если ты веришь во что-то, не говори, что это неправильно

в) не сообщай о своей некомпетентности во время адекватных мероприятий

\section{Maxim of Relevance}

будь релевантным

\section{Maxim of Manner}

будь искренним, открытым

а) избегай неопределенных вопросов

б) держись подальше от неопределенности

в) кратко сформулировай идею

г) будь дисциплинированным [3, с.45-46].

Правило вежливости Р. Лакофа (1973) с рядом суб- 
правил, принцип вежливости Дж. Лича с "maxims", комплементы стратегий вежливости П. Брауна и Дж.С. Левинсона $(1978,1987)$, фрейм Грайс Г. Пола, максимальная информативность и четкости речевых «maxim»; "maxims" и стратегии правил вежливости выступают в качестве социальных вопросов. Дж.Лич отмечает, что «РP maxim» не имеют одинакового характера для всех культур. Основной целью социо-прагматики является изучение того, что происходит между СР и РР в различных обществах $[4, c .80]$. С дискурсивной и прагматической точки зрения im/politeness охватывает микро-, макро-, мезо- уровни. Хотя дискурс и прагматика одинаковы, мнения, на которых они сосредоточены, различны.

Таким образом, одной из главных функций при дело- вой переписке является приобретение умения воспринимать культуру носителей данного языка. Этот процесс идет не в области опыта, входя в разряд высших умений, а зависит только от грамотности человека, уровня его личностного развития, отношения к себе и миру. Таким образом, главная задача общения, как через язык документов, так и в той или иной форме, заключается в передаче информации и понимании передаваемой информации, которая реализуется в основном через документы, переписки. В конечном итоге передается информация, которая важна для каждого человека. Именно поэтому переписка выступает в роли информатора, руководствуясь порядком слов и значением, которое они выражают вместе. Общение длится дольше, когда оно взаимно.

\section{ЛИТЕРАТУРА}

1. Məmmədov A., Məmmədov M. Diskurs Tədqiqi. Bakı: 2016, $111 \mathrm{s.}$

2. Musayev E.Ә. Kargüzarlı̆ı̆n təşkili. Bakı: 2012, 1041 s.

3. Grice H. Paul. "Logic and conversation" in P.Cole and J. Morgan (eds), Syntax and Semantics, vol.3: Speech Acts. New York: academic Press, 1975, pp.45-46

4. Leech, Geoffrey. Principles of Pragmatics. London, Longman,1983, pp.45-80

5. Lakoff R. Language and Woman's Place. New York. Harper and Row. 1975, pp.64-87

6. Scollon, Ron and Suzanne W. Scollon. Intercultural Communication: A Discourse Approach, Oxford Blackwall, 1995, pp.33-49

с Гурбанова Саида Сади гызы (saidag8@rambler.ru).

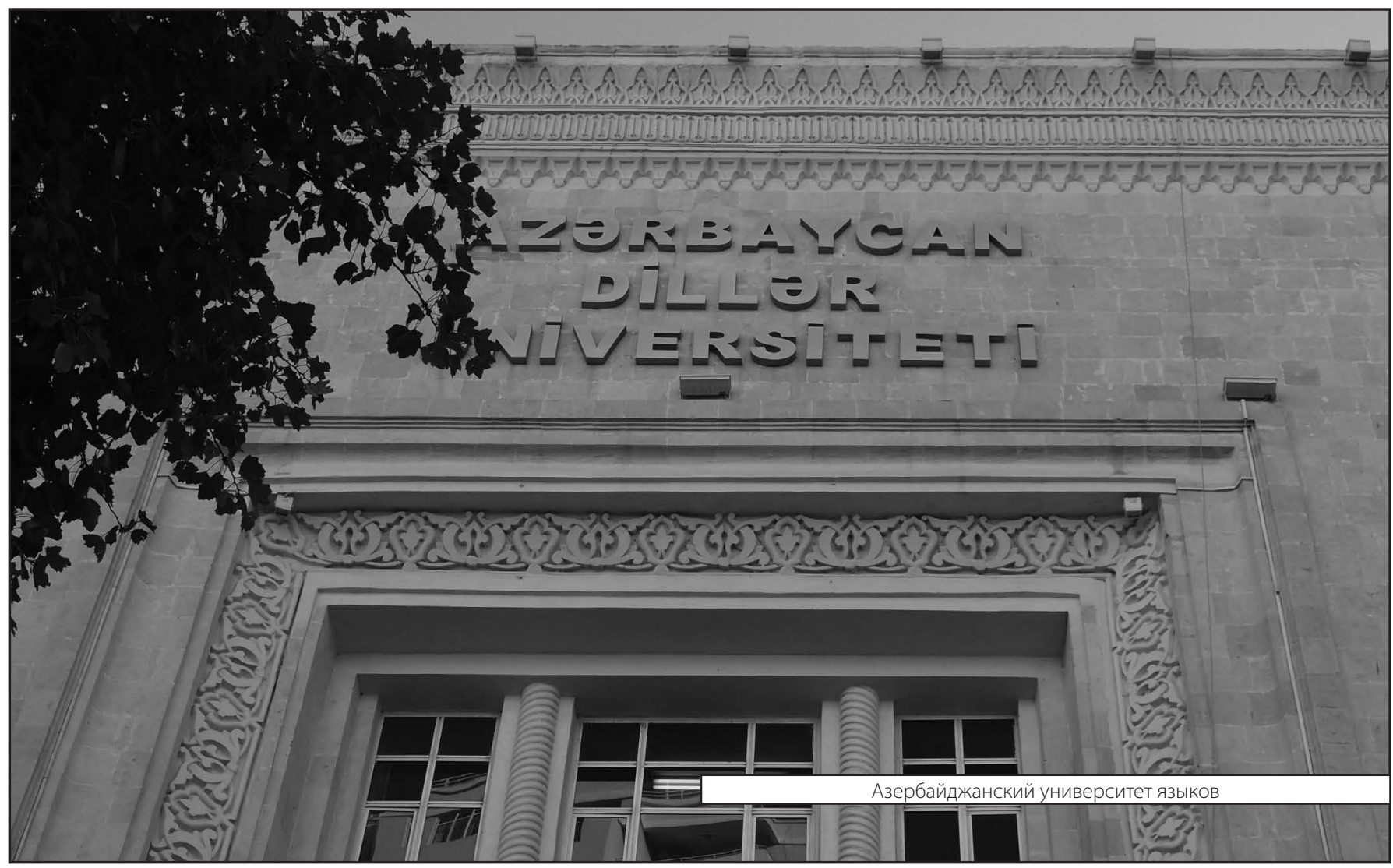

